\title{
Transformation of a large multi-speciality hospital into a dedicated COVID-19 centre during the coronavirus pandemic
}

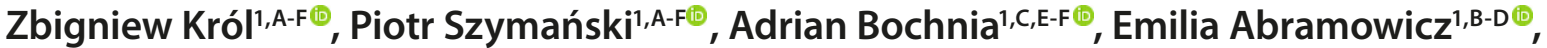

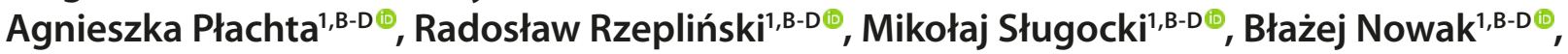

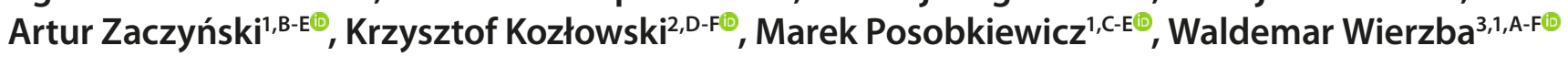 \\ ${ }^{1}$ MSWiA Central Clinical Hospital, Warsaw, Poland \\ ${ }^{2}$ Department of Constitutional Law, Jagiellonian University, Kraków, Poland \\ ${ }^{3}$ University of Humanities and Economics, Łódź, Poland \\ A - Research concept and design, B - Collection and/or assembly of data, C - Data analysis and interpretation, \\ $D$ - Writing the article, E-Critical revision of the article, $F$ - Final approval of article
}

Król Z, Szymański P, Bochnia A, Abramowicz E, Płachta A, Rzepliński R, Sługocki M, Nowak B, Zaczyński A, Kozłowski K, Posobkiewicz M, Wierzba W. Transformation of a large multi-speciality hospital into a dedicated COVID-19 centre during the coronavirus pandemic. Ann Agric Environ Med. 2020; 27(2): 201-206. doi: 10.26444/aaem/123801

\begin{abstract}
Ibstract
Introduction. The article describes the process of converting a large multi-specialized hospital into one dedicated to COVID-19 patients, and present established standards of work organization in all the wards and training system of the medical and supporting staff. The several weeks pandemic of the COVID-19 disease has forced the healthcare systems of numerous countries to adjust their resources to the care of the growing number of COVID-19 patients. Managers were presented with the challenge of protecting the healthcare workers from transmission of the disease within medical institutions, and issues concerning the physical and psychological depletion of personnel.

Materials and method. Based on analyses of the structure and work processes in Central Clinical Hospital (CCH) reconstructive strategic plan was developed. It included: division of existing wards into observation and isolation wards; installing locks; weekly plan for supplying personal protection equipment (PPE); designating new access to the hospital and communication routes; training of medical and supporting staff. The plan was implemented from the first days of conversion of the hospital. Results. The wards of the CCH were converted for observation and isolation, and each one was fitted with sanitary locks. There was a big improvement in the supply of PPE for the medical staff. Separation of the 'dirty' and 'clean' parts of the $\mathrm{CCH}$ were attained, and widespread intensive training not only protected personnel against infections, but also diminished unrest which was discernable at the beginning of conversion.

Conclusions. The transformation efforts will ultimately be appraised at the end of the epidemic, but the data looks encouraging. Two weeks after conversion, the testing of hospital Staff was started and by the end of April, 459 tests were had been conducted, of which only 11 were positive.
\end{abstract}

\section{Key words}

COVID-19, SARS-CoV-2, coronavirus pandemic, treatment in an infectious hospital, epidemic safety, organizational changes

\section{INTRODUCTION}

At the end of December 2019, a group of patients with pneumonia of unknown origin was observed in China who were linked epidemiologically with one of the wet markets in the city of Wuhan, Hubei Province [1]. A previously unknown coronavirus was identified, subsequently dubbed $2019-\mathrm{nCoV}$ [2], and later renamed SARS-CoV-2. The exact mechanism of its transmission has not been yet been fully understood; however, the prime mode is believed to be airborne. Other ways, such as faecal-oral or through fomites, have also been considered [3]. The virus is responsible for the development of an infectious disease known as Coronavirus disease 19 (COVID-19), targeting primarily the respiratory system. As of 19 April 2020, 2,241,778 cases of COVID-19 were confirmed, 152551 of which ended in death [4].

Address for correspondence: Waldemar Wierzba, University of Humanities and Economics, Łódź, Poland

E-mail: wwierzba@post.pl

Received: 08.05.2020; accepted: 09.06.2020; first published: 16.06.2020
Necessity for healthcare preparation for the pandemic. The developing pandemic has forced the healthcare systems of numerous countries to adjust their resources to care for the growing number of COVID-19 patients. Rationalization of work, proper clinical management and preventing the spread of infection play a crucial role in the whole process, not only for the SARS-CoV-2 infected patients, but also for the medical personnel and healthy individuals. Governments and hospital managers were presented with the challenge of protecting healthcare workers from the transmission of coronavirus within medical institutions, and issues of physical and psychological depletion, the latter of which were caused by major safety concerns expressed by the staff [5]. The factors contributing to unrest among the employees were shortage of the proper amount of quality personal protection equipment (PPE) in hospitals, lack of up-to-date knowledge about the new pathogen, and the means which may prevent infection and broad spread of the disease, as well as high exposure risk [6]. In order to tackle those problems, a clear and concise set of dedicated work protocols had to be developed which took into consideration the dynamics of 
the epidemiological situation, and the transfer of unskilled personnel from other disciplines [7].

Evolution of the SARS-Cov2 epidemic in Poland. The first case of COVID-19 in Poland was confirmed on4 March 2020 [8]. The number of verified infections rose to 49 , with one fatal case on 13 March [9], prompting the Minister for Health to issue a regulation Act on the same day which introduced a nationwide state of epidemic emergency in to meet to the rapidly increasing number of SARS-CoV-2 infections in the country [10]. The Act imposed limitations on trade and usage of certain goods, such as FFP2/FFP3 respirators. Within the next week, the number of confirmed cases surged to 325 , with death toll rising to 5 [11], resulting in the introduction of an epidemic state in Poland on 20 March 2020 [12]. Three days earlier, acting under congruent Acts [13], the Masovian Province decided to convert the Central Clinical Hospital of the Ministry of the Interior and Administration in Warsaw $(\mathrm{CCH})$ into a COVID-19 infectious diseases hospital - a multi-specialized centre to provide services to patients with SARS-CoV-2 infections and significant comorbidities (e.g. COVID-19 patients with acute coronary syndromes) or requiring special services (e.g. deliveries in SARS-CoV-2 positive pregnant women) [14].

The hospital administration and employees were confronted with the challenge of preparing the medical staff for new working conditions. In order to do so, a team was formed with the task of developing special rules of conduct in wards, planning of red and green zones and transportation routes, drawing-up procedures for PPE-usage, and conveying these protocols to the whole staff through a central training system.

\section{OBJECTIVE}

The aim of the study was to describe the process of converting a large, multi-specialized hospital (Fig. 1) into a dedicated COVID-19 speciality hospital, and present established standards of work organization in all wards and the training system of medical staff.

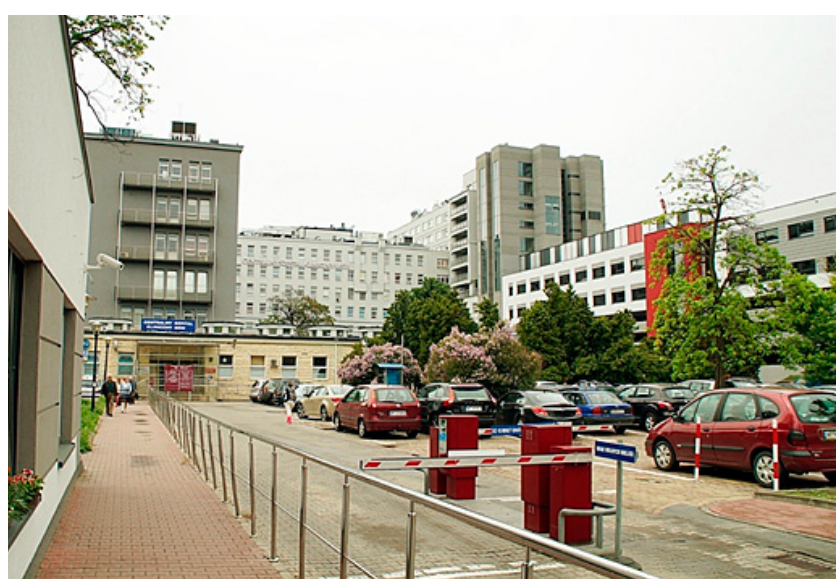

Figure 1. Central Clinical Hospital of MSWiA - before transformation into a dedicated COVID-19 centre

The CCH of the MSWiA in Warsaw is situated on a 16 hectare lot consisting of 31 buildings of different sizes, occupying a combined area of nearly 87,000 square meters. The buildings were constructed between 1950 - 2012 and differ in height and construction in terms of the type of staircases, lift shafts and lift mechanisms. In 20 of the buildings, patients are provided with medical care. Inpatient care is provided on 27 wards and clinics which together contain over 850 beds, in addition to 14 diagnostic facilities, 4 outpatient clinics and 39 specialist clinics. A total of nearly 15,000 surgeries were performed in 2019, 120,000 patients were hospitalized and over 100,000 people were attended to in the Emergency Ward. The huge complexity of the $\mathrm{CCH}$ represented an enormous organizational and logistical challenge to the staff responsible for its immediate transformation into a dedicated COVID-19 centre.

\section{ORGANIZATION OF WORK IN THE HOSPITAL}

The first objective of the team was to study available materials regarding COVID19-dedicated hospitals. The primary sources of reliable information were documents issued by the World Health Organization (WHO) [15], the Wuhan doctors' COVID-19 handbook [16], the Centers for Disease Control and Prevention (CDC) in the USA, and National Health Service (NHS) materials on the matter in the UK.

Division into observation and isolation wards. One of the first decisions was to divide the existing wards into observation and isolation wards. The former are units where patients suspected of COVID-19 but whose condition is too severe for them to remain in home quarantine, await the results of the rRT-PCR tests for SARS-CoV2. The rationale behind their organization lay in the fact that at the initial pandemic phase, waiting times for test results exceeded 24 hours. Isolation wards, in turn, were dedicated exclusively to patients with confirmed COVID-19 in order to manage both complications of the disease and concomitant diseases.

In both cases, the wards were rearranged in a way to relocate the administrative and social spaces, such as physicians' and nurses' offices outside the isolation areas and separate isolation zones by airlocks. Communication between the isolation zones and relocated administrative areas was established via visual systems and walkie-talkie radios (Fig. 2).

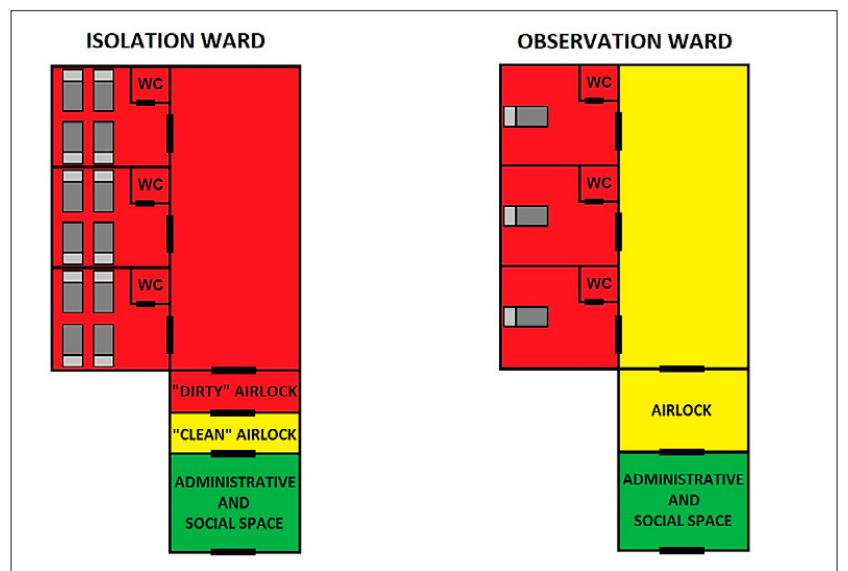

Figure 2. Work organization scheme of the hospital wards: isolation and observation. The relevant zones are marked in colour. In an isolation ward, the corridor adjoining patients' rooms was considered a 'red' zone, hence all rules concerning PPE equally pertained to patients' rooms and corridors, whereas in the observation areas, additional mini-locks were installed at the entrance to each room, where staff removed external surgical gowns and gloves before leaving the room into a 'yellow' zone. Patients were not allowed to leave these rooms 
Work organization in the isolation ward. In the isolation wards, the patients' rooms, corridors and procedure rooms were regarded as the 'red' zone. While on duty in the red zone, the staff were attired in standard PPE, which were removed in the two-step airlock after each shift. The outermost pair of gloves were changed after necessary care was provided to each patient. The maximal duration of work in the 'red' zone was set at 4 hours, which allowed employees to take 2 breakes during each 12-hour shift, and allowed for predictable calculation of PPE usage.

The WHO recommends FFP2/FFP3 class respirators to be used only while performing aerosol-generating procedures; otherwise, surgical masks are sufficient [15]. That said, as the afore-mentioned procedures are very likely to be conducted during every shift, the staff were urged to use FFP2/FFP3 respirators at all times.

Work organization in the observation ward. As the aetiology of the respiratory symptoms noted in patients in the observation wards was unknown, every patient was placed in a separate room in order to avoid cross-infections. Sickrooms are regarded as 'red' zones and corridors as 'yellow' zones. Changing the PPE takes place after leaving each patient's room and entering another. As it was impossible to organize actual airlocks at the entrance of every room, removal of PPEs takes place partly while still in patient's room and partly out of it. Therefore, the corridor was not considered to be a 'clean' zone and the staff were recommended to wear mask there. At the entrance of every patient's room, hand disinfectant, waste bin, table for face shield and goggles were available.

The type of work on the observation ward results in a high consumption of PPE, particularly of the disposable type, especially the respirators, as the face shields and goggles can be disinfected and used again. Therefore, the staff were advised to wear an FFP2/FFP3 respirator before entering the ward via the airlock. While the rest of $\mathrm{t}$ shift.

Adaptation of PPE usage procedures. Drawing upon the cited sources, donning and doffing procedures for isolation and observation wards were adapted. In the former case, gearing-up takes place in the 'green' zone and undressing in the airlocks. The protocol in the observation units was different: the staff change, scrubs and dons the respirator in the airlock and the rest of the PPE in the dedicated place, before entering patient's room. The gown and outer pair of gloves are discarded before leaving the sickroom, whereas face shield, cap, goggles and inner pair of gloves - in the corridor. Detailed instructions are provided in supplementary materials.

Designating new access and communication routes. In parallel with installation of locks, preparation of internal instructions, and training of the staff, it was decided to limit the number of entrances to the hospital's buildings, and designate specific entrances for patients with suspected SARS-Cov2. Under normal circumstances, there are 34 entrances to the hospital used by patients, visitors, supply staff, export of waste, as well as the CCH of the MSWiA staff. Considering the structure of the buildings, availability of internal communication, unusual localization, as well as needs of specific units, e.g. the dialysis station or radiotherapy laboratory, we chose to leave 6 entrance. Two buildings, because of the character of medical care provided in them, were only accessible from inside the hospital, and patients could only enter the hospital thought the Emergency Department (ED) which was also the first unit of the hospital to be divided into 'clean' and 'dirty' zones, along with the strengthening of PPE requirements and staff training.

In the next phase, the routes through which infected patients would be transported were separated in order to reduce the risk of infections among the staff, to provide an uninterrupted supply of medicaments, materials and food, and facilitate the transport of samples to laboratories. After installation of locks in the specific wards, the staff were obliged to change their outer PPE each time they left the ward. In order to limit the amount of times a person had to go through a lock, it was decided to organise separate transports from the pharmacy, laboratories, warehouses, and for waste. The decision was also motivated by the need to economise on PPEs, especially in the first days after the transformation.

After thorough analysis of the buildings and locations of lift shafts, it was decided to use Level 1 exclusively for transporting patients and Level -1 to transport necessities and as a communication route for the staff. Specific lifts were dedicated and marked with the word 'COVID' for patients and others, and 'clean' lifts for staff and materials. Additionally, exits from the 'clean' lifts on Level 1 and limited exits from the 'COVID' lifts on Level -1 were blocked. Allowing for the limited possibility to exit, 'COVID' lifts, of necessity, were also used during specific hours to transport waste and corpses. After each use, the lifts and routes were disinfected. The disinfection process was carried out 3 times a day, and each time it was reported by the staff. Figure 3 presents the exemplary routes at basement (A), ground floor (B) and first floor (C).

\section{PPE-USAGE TRAINING SYSTEM}

Aims of the central training system for medical staff. Devising the plan for the central training system aimed to present the proper choice and application of PPEs, to enable every trainee to practice PPE donning and doffing, and reassure the staff that the means of protection provide adequate safety at work. The key intention was for every member of the staff to learn how to work using the PPE under instructors' supervision. Therefore, a simple simulation of an airlock was arranged in one of hospital's conference rooms (Fig. 4), and a team of instructors formed

The PPE-usage training system developed consisted of two stages. The first was conducted by 2 instructors - one demonstrating the procedures of proper donning and doffing step-by-step, while the other narrated and described individual actions, occasionally adding general comments regarding the application of PPE. The verbal description provided by one of the instructors emphasised the correct order of the procedures (Supplement 1) and the places in which they ought to be performed.

Each group of trainees was highly diversified in terms of either position held or type of ward. Acknowledging all these differences, details of the procedure were adapted to the profile of each group. In the groups comprised mostly of staff from the observational units, the importance of changing protective PPE between consecutive visits in different sickrooms ase emphasised. It was clearly underlined which elements of PPE were to be removed while still in 


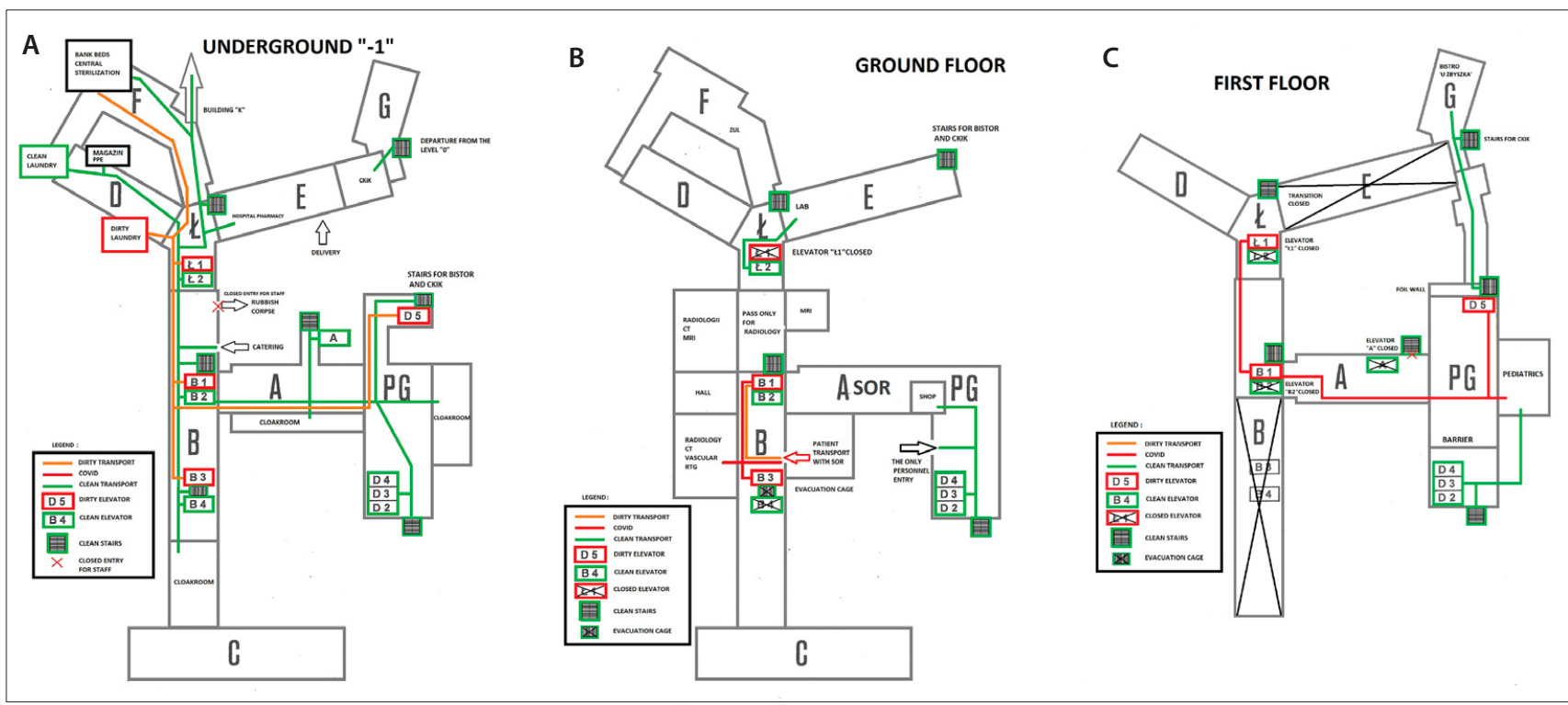

Figure 3. A) Basement dedicated exclusively for hospital staff and communication between buildings. B) Ground floor -Emergency Department (ED), the only point of admission of COVID-19 patients. They are transported from the ED to lift B1 or B3, depending on which ward they will be hospitalised; wards are denoted with capital letters. C) First floor - main communication route for infected patients between Emergency Ward, imaging laboratories labs and wards. Patients are transported only through dedicated routes by staff wearing full PPE.

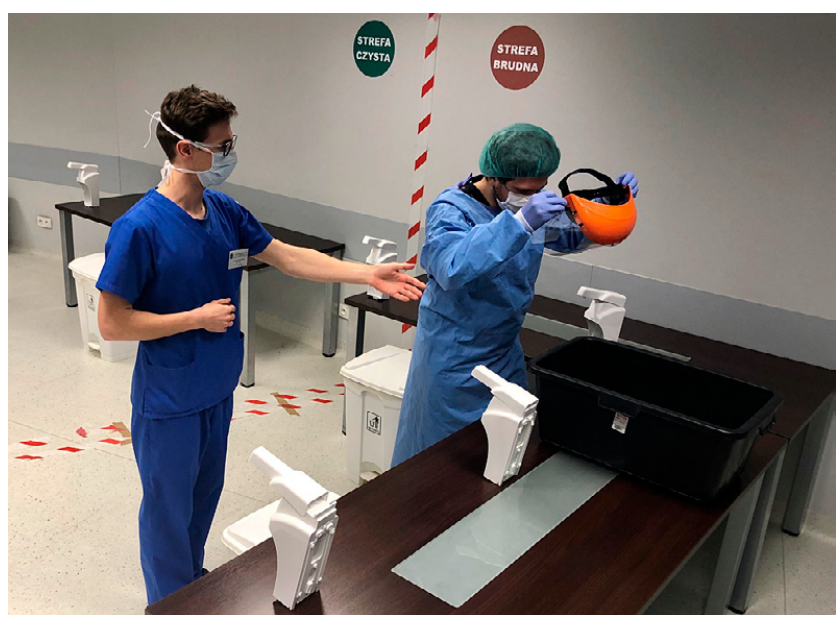

Figure 4. Airlock simulation in one of the conference rooms. The instructor guides the trainee through the procedure of removing personal protective equipment.

patient's room, and which were to be doffed outside. The staff of isolation wards were instructed to work in 4-hour shifts, wearing the same PPE during each shift, changing only the external pair of gloves between attending to patients. In groups with a high representation of operating theatre personnel, nuances were focussed on which were considered important in their work, especially those concerning changing their previous PPE donning habits to safer ones.

The second part of the training, conducted by an 8-person team, consisted in donning and doffing of PPEs by every participant, under an instructor's personal supervision. The individual character of this stage allowed each trainee to clarify specific aspects of PPE-usage related to their work.

One training session for a standard 15-person group took about 45 minutes. The first part lasted about 15 minutes, leaving about 30 minutes for the second. Groups were enrolled by telephone. In order to raise the efficacy of the training system, it was decided to conduct 2 sessions simultaneously in 2 rooms. Diversification of groups allowed the participants to exchange their experiences and concerns; on the other hand, more uniform groups enabled dealing with the issues of specific wards.

Ward cleaning staff training system. According to the WHO recommendations, the cleaning staff of COVID-19dedicated wards should wear special PPE, appropriate for the character of their work [15], which entails exposure to bio-hazardous materials, and prolonged presence in a patient's environment. During the PPE-usage training sessions, cleaning personnel displayed concern regarding the conversion of their workplace into an infectious hospital and resulting changes in work procedures. Therefore, it was decided to organize and conduct another training series, this time dedicated to the cleaning staff.

Aims of ward cleaning staff training system. In cooperation with hospital's Infections Team, a training schedule was devised which took into account the different work rules in the observation and isolation wards. The programme entailed: revising proper PPE usage for sanitary duty, equipping and handling the trolley, choosing and using adequate cleaning agents, ways of cleaning the COVID-19 wards, disposal and transport of medical waste. The groups consisted of up to 5 people and the training took about 30 minutes, depending on participants' commitment. One of the conference rooms was adapted to create a simplified ward simulation, comprised of areas crucial for cleaning staff duty (Fig. 5).

Course of ward cleaning staff training sessions. Training sessions commenced with a demonstration of the work scheme in a created model of either an observation or isolation ward. It was intended that the conduct of the different work in 2 types of wards would be the principal message of the training. One of the instructors commented on each of the presented activities. The demonstration and the discussion which followed all referred to the model of the ward, so that the verbal message would be augmented by visual stimulus. As the training time-span, was limited by the necessity of continuous work of staff in the wards, a 


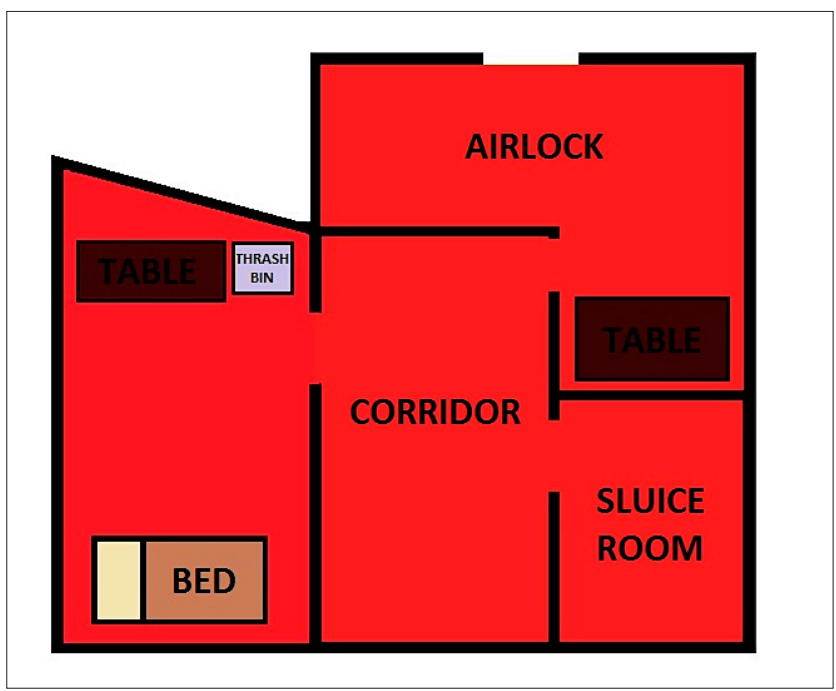

Figure 5. Conference room adaptation for the training of ward cleaning staff in the area of cleaning wards and airlocks

compromise had to be found which provided the best tuition in the shortest possible time. In the light of these facts, it was decided that trainees' individual practice of the activities would not be incorporated into the schedule of training sessions. The consequent discussion allowed the staff to address unclear issues of the procedure, and raise questions regarding either the activities presented, or concerns related to their application in practice.

On-site visits in wards. During PPE-usage training, a need to assist individual wards in adopting the general safety recommendations to their specific conditions was clearly noticed. In order to address these necessities, the training team met with ward nurses in each department.

Exemplary ward organization schemes. In one of the departments working as isolation ward, a 2-step airlock was constructed across the corridor (Fig. 6A). One of the offices in the 'clean' zone was designated as the donning room, while one of the sickrooms was rearranged as a 'dirty' airlock, allowing the staff to use the shower at the end of the shift.

The Department of Cardiac Surgery proposed a wellconceived solution to ensure the safety of both the patients and the personnel. They decided to make use of both of their operating theatres during one surgery - the first for induction of anaesthesia and intubation and the second for the main surgical procedure. The idea behind this was to provide a separate space for carrying out aerosol-generating procedures. Moreover, the operating team were to prepare for the surgery in one scrub room and remove PPE in another, which divided the 'clean' and 'dirty' procedures, thus allowing one-way movement in the surgical block.

\section{RESULTS OF TRAINING SYSTEM}

Medical staff training. Within the 2 -week period, over 1,100 employees of the Central Clinical Hospital of the Ministry of Interior and Administration enrolled in both training programmes (PPE-usage + ward cleaning). Among the participants of the PPE-usage training, there were representatives of the medical professions, administrative

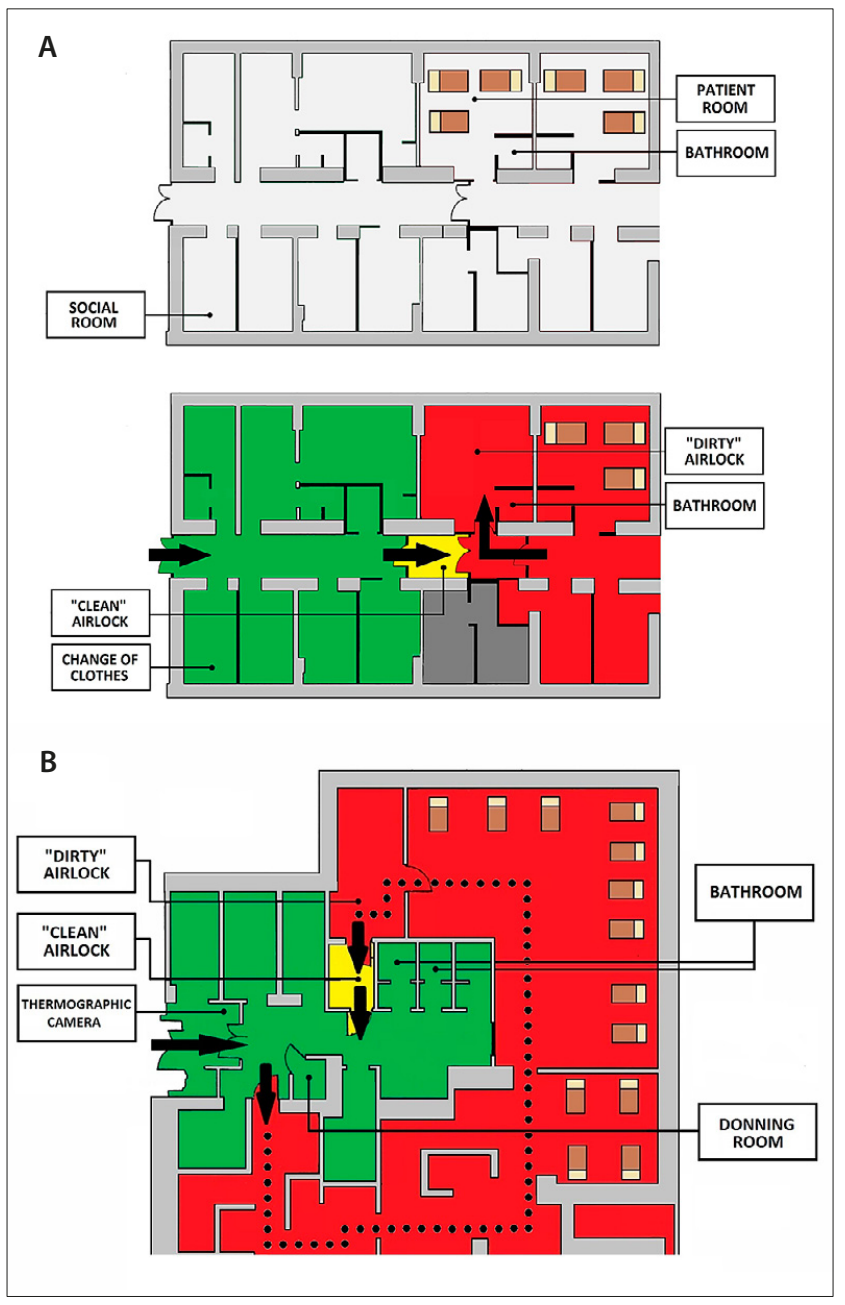

Figure 6. Work reorganization diagrams in two hospital exemplary units. A) Internal medicine department - view before (above) and after (below) reorganization. The airlock was created by placing walls across the corridor and excluding one of the patient rooms from use. B) Emergency Department - local conditions allowed the separation of entry and exit from the ward, introducing one-way traffic

personnel and cleaning staff. A group of military personnel were also trained who were temporarily referred to the hospital to assist with its conversion. The second training programme was devoted exclusively to the cleaning staff duties.

Implementation of new wards organization schemes. The central training system, based on reliable sources of upto-date knowledge, allowed implementation of uniform safety recommendations in the whole institution, which in turn facilitated proper organization of work, both within individual wards and the whole hospital. The choice of a central training system as the method of imparting the recommendations to the personnel proved to be a sound decision. Training sessions allowed direct contact between the instructors and participants, and enabled individual members of staff to practice the demonstrated procedures, which ensured that the instructions had been understood and performed appropriately. Attendees found this method to be comprehensible and accessible. An ample team of instructors allowed the training to be more efficient and thus completed in a shorter time, expediting the conversion of the hospital into an infectious institution. 
Reassurance of work safety among medical staff. An adjunctive objective of the training system was to reassure the personnel who exhibited pronounced concern about their personal safety in the current epidemiological situation. During the training sessions, the full spectrum of stress reaction and difficulties was observed in the adaptation to the new working and social conditions. In order to minimize any doubts, a set of concise and clear safety procedures we developed. In the process, local conditions of individual wards were taken into account in attempt to facilitate the introduction of the new regulations within the unit. The ordered procedures concerning the use of PPE were printed and given to the participants at each training station, which was acknowledged and appreciated by the participants. It was not uncommon for the staff to ask the instructors to share procedures in printed form, either for their own use or for further distribution among other employees on the ward. During the ward cleaning training sessions, the programmes were printed and supplied to the attendees. The schemes provided concerned the issues most crucial for the cleaning personnel, especially during the ongoing pandemic, focusing on the conduct differences in the observation and isolation wards. In the course of both training programmes, the staff could consult with the instructors on issues concerning personal safety, contents of recommendations, and problems encountered in the process of their implementation. The instructors addressed these concerns with understanding, reassuring the members of staff that, if performed properly, the presented procedures and PPE guaranteed adequate safety at work. All the issues not covered by the developed protocols were resolved on an ongoing basis in accordance with the credible sources of knowledge, and subsequently consulted with hospital's Infections Unit. This allowed the expansion of the recommendations and keep them up-todate, while taking into consideration the problems reported by the staff during the training sessions.

\section{CONCLUSIONS}

The developing pandemic and the decision to convert the Central Clinical Hospital of the Ministry of the Interior and Administration to an infectious hospital dedicated to treating COVID-19 patients forced the personnel to reorganize the whole institution. We describe our The experiences, present established procedures, and efficient way of putting them into practice through the training system and on-site visits in wards have been described. Ready-to-use work organization schemes and procedures we provide which could be easily adapted by the staff of other hospitals.

Although the transformation efforts will ultimately be appraised at the end of the panpidemic, there are good reasons for optimism. While the numbers of health personnel infected with SARS-CoV-2 worldwide, and in Poland in particular, are high, the data obtained seem encouraging. Testing of the hospital staff (personnel at risk over 2,000) started on $26 \mathrm{March}$, and concerned those who had infection symptoms 7 days after declared contact with a sick person. By the end of April, 459 tests had been conducted of which only 11 were positive; three employees had been infected during intensive resuscitation procedures while the others were infected outside the hospital.

\section{REFERENCES}

1. Zhu N, Zhang D, Wang W, Li X, Yang B, Song J, et al. A Novel Coronavirus from Patients with Pneumonia in China, 2019. N Engl J Med. 2020; 382(8): 727-33. https://doi.org/10.1056/NEJMoa2001017

2. Lu R, Zhao X, Li J, Niu P, Yang B, Wu H, et al. Genomic characterisation and epidemiology of 2019 novel coronavirus: implications for virus origins and receptor binding. The Lancet 2020; 395(10224): 565-74. https://doi.org/10.1016/S0140-6736(20)30251-8

3. Ciotti M, Angeletti S, Minieri M, Giovannetti M, Benvenuto D, Pascarella S, et al. COVID-19 Outbreak: An Overview. Chemotherapy 2020; 1-9. https://doi.org/10.1159/000507423

4. World Health Organization. Coronavirus disease 2019 (COVID-19) Situation Report - 90 https://www.who.int/docs/ default-source/coronaviruse/situation-reports/20200419sitrep-90-covid-19.f?sfvrsn $=551 \mathrm{~d} 47 \mathrm{fd} \_4 \& \mathrm{fbclid}=\mathrm{IwAR} 1$ AnDB2x5xCFUtHCFVmMXeVc5yBg33aun5wDsn6eAxfnxeJoFi_ pi28r_A (access: 2020.05.01)

5. Phua J, Weng L, Ling L, Egi M, Lim C-M, Divatia JV, et al. Intensive care management of coronavirus disease 2019 (COVID-19): challenges and recommendations. Lancet Respir Med. 2020. https://doi.org/10.1016/ S2213-2600(20)30161-2

6. Zhang W, Wang K, Yin L, Zhao W, Xue Q, Peng M, et al. Mental Health and Psychosocial Problems of Medical Health Workers during the COVID-19 Epidemic in China. Psychother Psychosom. 2020; 1-9. https://doi.org/10.1159/000507639

7. Lee CCM, Thampi S, Lewin B, Lim TJD, Rippin B, Wong WH, et al. Battling COVID-19: Critical care and peri-operative healthcare resource management strategies in a tertiary academic medical centre in Singapore. Anaesthesia 2020. https://doi.org/10.1111/anae.15074

8. World Health Organization. Coronavirus disease 2019 (COVID-19) Situation Report - 44 https://www.who.int/docs/default-source/ coronaviruse/situation-reports/20200304-sitrep-44-covid-19. pdf?sfvrsn=93937f92_6 (access: 2020.05.01)

9. World Health Organization. Coronavirus disease 2019 (COVID-19) Situation Report - 53 https://www.who.int/docs/default-source/ coronaviruse/situation-reports/20200313-sitrep-53-covid-19. pdf?sfvrsn=adb3f72_2 (access: 2020.05.01)

10. Rozporządzenie Ministra Zdrowia z dnia 13 marca 2020 r. w sprawie ogłoszenia na obszarze Rzeczypospolitej Polskiej stanu zagrożenia epidemicznego.

11. World Health Organization. Coronavirus disease 2019 (COVID-19) Situation Report - 60 https://www.who.int/docs/default-source/ coronaviruse/situation-reports/20200320-sitrep-60-covid-19. pdf?sfvrsn=d2bb4f1f_2 (access: 2020.05.01)

12. Rozporządzenie Ministra Zdrowia z dnia 20 marca 2020 r. w sprawie ogłoszenia na obszarze Rzeczypospolitej Polskiej stanu epidemii.

13. Ustawa z dnia 2 marca 2020 r. o szczególnych rozwiązaniach związanych z zapobieganiem, przeciwdziałaniem i zwalczaniem COVID-19, innych chorób zakaźnych oraz wywołanych nimi sytuacji kryzysowych.

14. Polecenie Wojewody Mazowieckiego z dnia 17 marca 2020 r. (WZII.967.28.2020).

15. World Health Organization. Rational use of personal protective equipment (PPE) for coronavirus disease (COVID-19): interim guidance, 19 March 2020 https://apps.who.int/iris/bitstream/ handle/10665/331215/WHO-2019-nCov-IPCPPE_use-2020.1-eng. pdf (access: 2020.05.01)

16. Tingbo L. Handbook of COVID-19 Prevention and Treatment. 2020. 